\title{
A study to identify various bacteria in conjunctiva among the diabetic and non-diabetic individuals
}

\author{
Sarma S.S. ${ }^{1}$, Chandra T.J. ${ }^{2}$ \\ ${ }^{1}$ Dr. S. Srinivasa Sarma, Assistant Professor, Department of Microbiology, Rangaraya Medical College, Kakinada, Andhra \\ Pradesh, ${ }^{2}$ Dr. T. Jaya Chandra, Associate Professor, Department of Microbiology, GSL Medical College, Rajahmundry, Andhra \\ Pradesh, India.
}

Corresponding Author: Dr. T. Jaya Chandra, Associate Professor, Department of Microbiology, GSL Medical College, Rajahmundry, Andhra Pradesh, India. Email: chanduthegreat2014@gmail.com

\begin{abstract}
Introduction: Diabetes mellitus is a multi-factorial disease that can affect all ocular structures. With this a study was conducted to isolate and identify the organisms from the conjunctival flora of normal and diabetic population. Materials and methods: Study was conducted in department of Microbiology, GSL Medical College, Rajahmundry. Surgically removed cataract lens were collected from diabetic and nondiabetic individuals in sterile nutrient broth and transported immediately to Microbiology laboratory for culture and sensitivity testing, processed and identified as per the standard protocol. Isolates were subjected to antibiotic sensitivity analysis using Kirby Bauer disc diffusion method. Results: During the study period, 30 samples each were collected from diabetic and non-diabetic individuals who underwent cataract. Culture positive results were more (76.6\%) in diabetic patients; Isolate wise, gram positive cocci were $53.3 \%$, 57\%, gram positive bacilli (GPB) were $26.6 \%$ each and gramnegative bacilli (GNB) were 3.3\%, 19.8\% respectively in non-diabetic and diabetic patients. statistically the difference was not significant. And the isolates were increased with age. Conclusion: The prevalence of isolation was almost similar among the non-diabetics and diabetic population. In both groups, rate of isolation was increased with age and no significant drug resistance was observed.
\end{abstract}

Keywords: Among, conjunctiva, Cataract, Diabetes, Prevalence.

\section{Introduction}

The conjunctiva is a transparent mucous membrane lining the internal surfaces of the eyelids and the orbital globe. The conjunctival flora is found on the ocular surface of healthy individuals have an important role in the maintenance of normal conjunctival functions and the prevention of ocular infections [1].

Conjunctival flora begins forming at birth and continues to increase over the lifespan. Flora may vary depending on environment, age, immunity, ocular surface diseases, systemic diseases, climate, region and general hygienic conditions [2]. The flora of the ocular surface consists more of gram-positive Microorganisms [3].

Resident and transient are the 2 types of ocular flora. Resident ocular flora includes Staphylococcus epidermidis, Diphtheroids, Staphylococcus aureus, Lactobacillus species and Propionibacterium species [4]. Whereas transient ocular flora inhabits the eye for short periods and

Manuscript received: $10^{\text {th }}$ November 2019

Reviewed: $20^{\text {th }}$ November 2019

Author Corrected: $26^{\text {th }}$ November 2019

Accepted for Publication: $3^{\text {rd }}$ December 2019 cannot be consistently recovered in consecutive cultures. This includes Pseudomonas from the hospitalized patients and Streptococcus, Pneumococcus and Haemophilus in children [4].

Diabetes mellitus (DM) is a multi-factorial disease that can affect all ocular structures, especially the retina. Diabetic patients have a higher risk of postoperative endophthalmitis than non-diabetic Patients [5]. The flora of the conjunctiva, eyelid and even the nasal mucosa form the majority of pathogenic microorganisms involved in postoperative endophthalmitis (PE) [6].

The visual outcome of diabetic patients after PE is worse than that of non-diabetics $[7,8,9]$. In developed countries, there is the threat of an epidemic growth of DM prevalence $[10,11,12]$ in particular in the elderly.

With this a study was conducted to isolate and identify the organisms from the conjunctival flora of normal and diabetic population.

Pathology Update: Tropical Journal of Pathology \& Microbiology Available online at: www.medresearch.in 1021|P a g e 


\section{Materials and Methods}

Settings: Study was conducted in the department of Microbiology, GSL Medical College.

Duration of study: Study was conducted for 2 months, Feb 2019 to March 2019.

Sampling method: Random sampling was considered in this study.

Inclusion criteria: Individuals aged $>18$ years, who submitted informed consent, were included in the study.

Exclusion criteria: Individuals aged V18 years, who didn't submit informed consent, were excluded in the study.

Sample size: All the individuals who satisfy the inclusion criteria during the study period were included in the study.

Ethical approval: Study protocol was approved by the institutional ethical committee.

Surgically removed cataract lens was collected from diabetic and non diabetic individuals in sterile nutrient broth and transported immediately to Microbiology laboratory for culture and sensitivity testing. The broths were incubated at $37^{\circ} \mathrm{C}$ for 24 hours, subcultured on Blood agar, MacConkey agar and Nutrient agar. Inoculated media were incubated aerobically at $37^{\circ} \mathrm{C}$ for 24 hours and examined for bacteria growth according to standard protocol.

After incubation growth was identified according to standard protocol and also by following previously described protocol [13, 14]. Isolated bacteria were identified by assessing colony characteristics, gram reaction and the following five tests: (1) catalase and coagulase, (2) hemolysis on blood agar, (3) biochemical tests including indole production, citrate utilization and urease production (4) triple sugar iron (TSI) agar tests for glucose, sucrose and lactose fermentation and hydrogen sulphide production and (5) oxidase test. Bacterial isolates were subjected to antibiotic sensitivity analysis using the Kirby Bauer disc diffusion method [14].

\section{Results}

During the study period, 30 samples each were collected from diabetic and nondiabetic individuals who underwent cataract. Culture positive $(\mathrm{CP})$ results were more $(76.6 \%)$ in diabetic patients; Isolate wise, gram positive cocci were $53.3 \%$, 57\%, gram positive bacilli (GPB) were 26.6\% each and gram-negative bacilli (GNB) were 3.3\%, 19.8\% respectively in non-diabetic and diabetic patients. statistically the difference was not significant (Table 1).

Table-1: Culture results in diabetic and non diabetic individuals.

\begin{tabular}{|c|c|c|}
\hline Organism & Non-Diabetic patient $(\mathbf{n}=\mathbf{3 0})$ & Diabetic patient $(\mathbf{n}=\mathbf{3 0})$ \\
\hline GPC & $16(53.3 \%)$ & $17(56 \%)$ \\
\hline GPB & $8(26.6 \%)$ & $8(26.6 \%)$ \\
\hline GNB & $1(3.3 \%)$ & $6(19.8 \%)$ \\
\hline CP & $23(76.6 \%)$ & $25(82.5)$ \\
\hline CN & $7(23.1 \%)$ & $5(16.5 \%)$ \\
\hline \multicolumn{2}{|c|}{ The Chi square statistic with Yates correction was 0.1042. P value is 0.746886. Not statistically significant }
\end{tabular}

When age wise considered, the culture positivity among the non-diabetics were $0,9.9 \%, 13.2 \%, 26.4 \%, 36.3 \%$ and $76.9 \%$ respectively in $0-15,16-30,31-45,46-60$ and $>61$ years age group; statistically there was no significant difference among the non-diabetics in culture positive results (Table 2).

Table-2: Age wise culture result among non-diabetic individuals.

\begin{tabular}{|c|c|c|c|c|c|c|}
\hline \multirow{2}{*}{ Age } & \multicolumn{5}{|c|}{ Culture report } & \multirow{2}{*}{ Total } \\
\cline { 2 - 6 } & GPC & GPB & GNB & Total & Sterile & \\
\hline $0-15$ & 0 & 0 & 0 & 0 & $4(13.2 \%)$ & $4(13.2 \%)$ \\
\hline $16-30$ & $2(6.6 \%)$ & $1(3.3 \%)$ & 0 & $3(9.9 \%)$ & $2(6.6 \%)$ & $5(16.5 \%)$ \\
\hline $31-45$ & $2(6.6 \%)$ & $1(3.3 \%)$ & $1(3.3 \%)$ & $4(13.2 \%)$ & $1(3.3 \%)$ & $5(16.5 \%)$ \\
\hline $46-60$ & $5(16.5 \%)$ & $3(9.9 \%)$ & 0 & $8(26.4 \%)$ & 0 & $8(26.4 \%)$ \\
\hline$>61$ & $7(23.1 \%)$ & $3(9.9 \%)$ & $1(3.3 \%)$ & $11(36.3 \%)$ & 0 & $11(36.3 \%)$ \\
\hline Total & $\mathbf{1 6 ( 5 2 . 8 \% )}$ & $\mathbf{8 ( 2 6 . 4 \% )}$ & $\mathbf{2 ( 3 . 3 \% )}$ & $\mathbf{2 6}(\mathbf{7 6 . 9 \% )}$ & $\mathbf{7 ( 2 3 . 1 \% )}$ & $\mathbf{3 3}(\mathbf{1 0 0} \%)$ \\
\hline
\end{tabular}

Pathology Update: Tropical Journal of Pathology \& Microbiology Available online at: www.medresearch.in $1022 \mid \mathrm{P}$ a g $\mathrm{E}$ 
Among the diabetic individuals, the culture results were $0,13.2 \%, 13.2 \%, 23.1 \%, 52.8 \%$ and $73.5 \%$ respectively in $0-15,16-30$, 31- 45, 46-60 and > 61 years age group; statistically there was no significant difference among the diagnostics in culture positive results (Table 3 ).

Table-3: Age wise culture results among diabetic individuals

\begin{tabular}{|c|c|c|c|c|c|c|}
\hline \multirow{2}{*}{ Age } & \multicolumn{5}{|c|}{ Culture report } & \multirow{2}{*}{ Total } \\
\cline { 2 - 6 } & GPC & GPB & GNB & Total & Sterile & \\
\hline $0-15$ & 0 & 0 & 0 & 0 & $2(6.6 \%)$ & $2(6.6 \%)$ \\
\hline $16-30$ & $2(6.6 \%)$ & $1(3.3 \%)$ & $1(3.3 \%)$ & $4(13.2 \%)$ & $1(3.3 \%)$ & $5(16.5 \%)$ \\
\hline $31-45$ & $3(9.9 \%)$ & $1(3.3 \%)$ & 0 & $4(13.2 \%)$ & $1(3.3 \%)$ & $5(16.5 \%)$ \\
\hline $46-60$ & $4(13.2 \%)$ & $1(3.3 \%)$ & $2(6.6 \%)$ & $7(23.1 \%)$ & $1(3.3 \%)$ & $8(26.4 \%)$ \\
\hline$>61$ & $8(26.4 \%)$ & $5(16.5 \%)$ & $3(9.9 \%)$ & $16(52.8 \%)$ & 0 & $16(52.8 \%)$ \\
\hline Total & $\mathbf{1 7}(\mathbf{5 6 . 1 \% )}$ & $\mathbf{8 ( 2 6 . 4 \% )}$ & $\mathbf{6 ( 1 9 . 8 \% )}$ & $\mathbf{3 1}(\mathbf{7 3 . 5 \% )}$ & $\mathbf{5 ( 1 6 . 5 \% )}$ & $\mathbf{3 6}(\mathbf{1 0 0} \%)$ \\
\hline
\end{tabular}

Table-4: Drugs susceptibility pattern for the isolates in non diabetics

\begin{tabular}{|l|l|}
\hline \multicolumn{1}{|c|}{ Organism } & \multicolumn{1}{|c|}{ Non diabetics } \\
\hline Staphylococcus aureus $(\mathrm{n}=10)$ & $\begin{array}{l}\text { Penicillin }(80 \%), \text { Ciprofloxacin }(80 \%), \text { Gentamycin }(80 \%), \text { Clindamycin }(60 \%), \\
\text { Cotrimoxazole }(80 \%), \text { Amikacin }(100 \%), \text { Erythromycin }(80 \%), \text { Vancomycin } \\
(100 \%), \text { Amoxyclav }(80 \%) .\end{array}$ \\
\hline CoNS $(\mathrm{n}=6)$ & $\begin{array}{l}\text { Penicillin }(90 \%), \text { Ciprofloxacin }(80 \%), \text { Gentamycin }(70 \%), \text { Clindamycin }(50 \%), \\
\text { Cotrimoxazole }(80 \%), \text { Amikacin }(90 \%), \text { Erythromycin (70\%), Vancomycin } \\
(90 \%), \text { Amoxyclav }(80 \%) .\end{array}$ \\
\hline Klebsiella $(\mathrm{n}=1)$ & $\begin{array}{l}\text { Ampicillin }(1000 \%), \text { Piparacillin }(60 \%), \text { Gentamycin }(0 \%), \text { Tobramycin }(100 \%), \\
\text { Erythromycin }(0 \%), \text { Piperacillin Tazobactum }(100 \%), \text { Amoxyclav }(100 \%) .\end{array}$ \\
\hline
\end{tabular}

Table-5: Drugs susceptibility pattern for the isolates in diabetics

\begin{tabular}{|c|c|}
\hline Organism & Diabetics \\
\hline Staphylococcus aureus $(n=11)$ & $\begin{array}{l}\text { Penicillin (73\%), Ciprofloxacin (73\%), Gentamycin (73\%), Clindamycin (45\%), } \\
\text { Cotrimoxazole }(55 \%) \text {, Amikacin }(100 \%) \text {, Erythromycin }(73 \%) \text {, Vancomycin } \\
(90 \%) \text {, Amoxyclav }(55 \%) \text {. }\end{array}$ \\
\hline $\operatorname{CoNS}(n=6)$ & $\begin{array}{l}\text { Penicillin }(84 \%) \text {, Ciprofloxacin }(66 \%) \text {, Gentamycin }(66 \%) \text {, Clindamycin }(50 \%) \text {, } \\
\text { Cotrimoxazole (83\%), Amikacin (83\%), Erythromycin (83\%), Vancomycin (66\%), } \\
\text { Amoxyclav (84\%). }\end{array}$ \\
\hline Klebsiella $(\mathrm{n}=2)$ & $\begin{array}{l}\text { Ampicillin }(50 \%) \text {, Piparacillin }(50 \%) \text {, Gentamycin }(50 \%) \text {, Tobramycin }(100 \%) \text {, } \\
\text { Erythromycin }(50 \%) \text {, Piperacillin Tazobactum }(100 \%) \text {, Amoxyclav }(50 \%) \text {. }\end{array}$ \\
\hline Pseudomonas $(\mathrm{n}=1)$ & $\begin{array}{l}\text { Gentamycin }(0 \%) \text {, Ciprofloxacin }(0 \%) \text {, Amikacin }(50 \%) \text {, Ampicillin }(50 \%) \text {, } \\
\text { Cotramoxazole }(0 \%) \text {, Ticarcillin }(100 \%) \text {, Tobramycin }(100 \%) \text {, Piperacillin } \\
\text { Tazobactum }(100 \%) \text {, Imipenem }(100 \%) \text {. }\end{array}$ \\
\hline Escherichia coli $(n=3)$ & $\begin{array}{l}\text { Ampicillin }(66 \%) \text {, Piparacillin }(66 \%) \text {, Gentamycin }(33 \%) \text {, Tobramycin }(100 \%) \text {, } \\
\text { Erythromycin }(33 \%) \text {, Piperacillin Tazobactum }(100 \%) \text {, Amoxyclav }(66 \%) \text {. }\end{array}$ \\
\hline
\end{tabular}

\section{Discussion}

In this study, culture positivity was $76.6 \%$ and $82.5 \%$ respectively for non-diabetics and diabetics. Statistically the difference was not significant. The available studies also reported similar findings. Mehmet Adam et al., [15] reported that bacterial isolations were determined as $38.5 \%$ in diabetic patients and $34.9 \%$ in nondiabetic individuals. In another study by Suresh K et al., of the 100 study participants, the investigators reported 148 culture positivity; Among this, 72 and 74 were culture positive, respectively in diabetics and non-diabetic [4]. Moreover, it was reported in the literature that the postoperative endophthalmitis is worse among diabetics than that of nondiabetics [9]. In this study, among non-diabetics, GPC (16; $53.3 \%$ ) is the predominant organism isolated followed by 
GPB $(8 ; 26.6 \%)$ and GNB $(1 ; 3.3 \%)$. In our previous report, out of 58 study participants, $64.2 \%$ were GPC, $7 \%$ were GNB and $29 \%$ were $\mathrm{CN}$ [3]. Among the diabetic participants, GPC $(17 ; 56.6 \%)$ is the predominant organism isolated followed by GPB $(8 ; 26.6 \%)$ and GNB $(6 ; 19.8 \%)$.

Totally, 7 (23.1\%) and $5(16.5 \%)$ were $\mathrm{CN}$ respectively in non-diabetics and diabetics. Suresh $\mathrm{K}$ et al., also reported similar findings, i.e. GPC (54) was the predominant isolate followed by GPB (13) and GNB (5) [4].

In the current report, among the diabetics, the rate of isolation was increased with age (Table: 3 ); statistically the difference was not significant $(\mathrm{P}>0.05)$. More than 60 years is the common age group that most of the patients require cataract surgery; it was reported that this age group is most vulnerable for diabetes especially in the developed countries $[15,16]$. Adam $M$ et al., also reported no significant differences between the groups in terms of demographic characteristics (gender, $\mathrm{p}=0.71$; age, $\mathrm{p}=0.89$ ) [17]. But in this study gender difference was not considered in this study; which is one of the limitations.

Among the isolates, Staph. aureus was the predominant organism isolated, 11 and 10 respectively among diabetics and non-diabetics. Followed by CoNS, 6 each, Esch. coli 3, 0 Klebsiella species 2, 1 and Pseudomonas 1,0, respectively among diabetics and non-diabetics (Table 5, 6).

Similar findings were reported in the available literature. In the diabetic category, Adam et al., also reported Staphylococcu aureus (30\%) as predominant isolate followed by Escherichia coli (20\%), CoNS (10\%) and Klebsiella pneumoniae (10\%) [17].

In another study by Natalia Pimentel Moreno et al., Staphylococcus epidermidis (82\%) is the predominant isolate, followed by Staphylococcus aureus (14\%), Proteus mirabilis (04\%) and S. epidermidis (04\%) [18].

In diabetics increased conjunctival flora with increased isolation of Staphylococcus aureus has been reported. In the literature $[19,20]$ whereas Ashok kumar et al. reported same isolates among the diabetics and non-diabetic individuals [21].

There was no significant drug resistance was detected in this study among the study participants (Table 4). However, decrease in drug sensitive isolates was detected among diabetics (Table 5). In addition to spread of drug resistance bacteria, improper usage of antibiotics is also cause for drug resistance.

But the cause was not found, this could be the limitation of the study. Whereas Suresh et al., reported the sensitivity pattern of Staph aureus alone due to easy development of drug resistance to various antibiotics [4]. It was reported that, among diabetics, 38\% Staph aureus strains were resistance to Eryhthromycin. Whereas in this study, 30\% strains were resistant to Erythromycin.

Limitations of the study: Small sample size and short duration are the limitations of this research.

\section{Conclusion}

The prevalence of isolation was almost similar among the non-diabetics and diabetic population. In both groups, rate of isolation was increased with age and no significant drug resistance was observed.

\section{What the study adds to the existing knowledge?}

Diabetes didn't influence the flora in ocular region.

\section{Authors contributions}

Dr. S Srinivasa Sarma: Literature survey, Paper writing, data analysis

Dr. T Jaya Chandra: Sample collection, Bench work, statistical analysis, paper writing

Funding: No funding sources

Conflict of interest: None declared

Ethical Approval: This study was approved by the Institutional Ethics Committee

\section{References}

1. Jawetz E, Melnnick LJ, Adelberg AE. Medical Microbiology $21^{\text {st }}$ ed. Prentice Hall International, USA; 1989; 18:275-278.

2. Manav G, Bilgin L, Gezer A. Conjunctival flora in normal population. Turk J Ophthalmol. 1992;12:121-124.

3. Satish K, Jaya Chandra T. Bacterial flora in the conjunctiva among the patients undergoing cataract surgery. Int J Res Med Sci. 2019;7(4):1208-1211. doi: http: // dx.doi.org/10.18203/2320-6012.ijrms20191326.

4. Suresha K, Mandavaa K, Kindob JA. Conjunctival flora in diabetics \& normal population - A comparative study. Sri Ramachandra J Med. 2014;7(2):1-4.

5. Cohen SM, Flynn HW JR, Murray TG, Smiddy WE. Endophthalmitis after pars plana vitrectomy, the postvitrectomy endophthalmitis study group. Ophthalmol. 1995; 102(5):705-712. doi: https://doi.org/10.1016/S01616420 (95)30965-7. 
6. Speaker M, Milch FA, Shah MK, Eisner W, Kreiswirth BN. Role of external bacterial flora in the pathogenesis of acute postoperative endophthalmitis. Ophthalmol. 1991;98 (5):639-649. doi: https://doi.org/10.1016/S0161-6420(91) 32239-5.

7. Phillips II WB, Tasman WS. Postoperative endophthalmitis in association with diabetes mellitus. Ophthalmol. 1994; 101 (3): 508-518. doi: https://doi.org/ 10.1016/S0161-6420(13)31268-8.

8. Desai P, Minassian DC, Reidy A. National cataract survey 1997-1998: a report of results of the clinical outcomes. Br J Ophthalmol. 1999;83(12):1336-1340. doi: http:// dx.doi.org/10.1136/bjo.83.12.1336.

9. Doft BH, Wisniewski SR, Kelsey SF, Fitzgerald SG, Endophthalmitis Vitrectomy Study Group. Diabetes and postoperative endophthalmitis in the endophthalmitis vitrectomy study. Arch Ophthalmol. 2001;119(5):650-656. doi:10.1001/archopht. 119.5.650.

10. Mainous III AG, Baker R, Koopman RJ, Saxena S, Diaz VA, Everett CJ et al. Impact of the population at risk of diabetes on projections of diabetes burden in the United States: an epidemic on the way. Diabetologia. 2007;50:934940. doi 10.1007/s00125-006-0528-5.

11. Frese T, Sandholzer H, Voigt S, Voigt R. Epidemiology of practitioners diabetes mellitus in German general consultation results of the SESAM 2-study. Exp Clin Endocrinol Diabetes. 2008;116(6):326-328. doi: 10.1055/s2008-1046805.

12. Magliano DJ, Shaw JE, Shortreed SM, Nusselder WJ, Liew D, Barr EL et al. Lifetime risk and projected population prevalence of diabetes. Diabetol. 2008;51(12): 2179-2186. doi: 10.1007/s00125-008-1150-5. Epub 2008 Sep 23.

13. Bailey \& Scott's Diagnostic Microbiology, Karan Fabiano Editor. Laboratory cultivation and isolation of bacteria, methods for bacterial identification. $12^{\text {th }}$ edition. Andrew Allen Publisher; 2012.
14. Chandra TJ, Lakshmi Prasanna, AV Rao. A study on isolation and identification of nosocomial infections causing bacteria on mobile phones of health care workers. Calicut Med J. 2011;9(1):e2.

15. ME Fernandez-Rubio, L Rebolledo-Lara, M MartinezGarci'a, M Alarco' n-Toma s Corte' s-Valde' s. The conjunctival bacterial pattern of diabetics undergoing cataract Surgery. Eye. 2010;24:825-834.

16. Cowie CC, Rust KF, Byrd-Holt DD, Eberhardt MS, Flegal KM, Engelgau MM et al. Prevalence of diabetes and impaired fasting glucose in adults in the US population: National Health and Nutrition Examination Survey 1999 2002. Diab Care. 2006;29(6):1263-1268.

17. Adam $\mathrm{M}$, Balcı $\mathrm{M}$, Bayhan HA, İnkaya CA, Uyar M, Gürda C. Conjunctival Flora in Diabetic and Nondiabetic Individuals. Turkish J Ophthalmol. 2015;45(5):193-196. doi: 10.4274/tjo.33230.

18. Natalia PM, Renaldo DM, Luciene BS. Aerobic bacterial microbiota of the conjunctiva in diabetic patients with normal and altered glycolated hemoglobin levels in two regions in Brazil. Arq Bras Talmol 2014;77(6):351354. doi: 10.5935/0004-2749.20140088.

19. Shanmugam P, M J, Susan S L. The bacteriology of diabetic foot ulcers, with a special reference to multidrug resistant strains. J Clin Diagn Res. 2013;7(3):441-445. doi: 10.7860/JCDR/2013/5091.2794. Epub 2013 Mar 1.

20. Gupta A, Orlans HO, Hornby SJ, Bowler IC. Microbiology and visual outcomes of culture-positive bacterial endophthalmitis in Oxford, UK. Graefes Arch Clin Exp Ophthalmol. 2014; 252(11):1825-1830. doi: 10.1007/ s00417-014-2658-7. Epub 2014 Jun 11.

21. Kumar MA, Kurien SS, Selvaraj S, Devi U, Selvasundari S. Comparison of different techniques of cataract surgery in bacterial contamination of the anterior chamber in diabetic and non-diabetic population. Indian $\mathrm{J}$ Ophthalmol. 2012;60(1):41-44. doi: 10.4103/0301-4738. 90486.

\section{How to cite this article?}

Sarma S.S, Chandra T.J. A study to identify various bacteria in conjunctiva among the diabetic and non-diabetic individuals. Trop J Path Micro 2019;5(12):1021-1025.doi:10.17511/ jopm.2019.i12.09 